\title{
Control Strategy of Permanent Magnet Synchronous Motor Used in Electric Vehicle
}

\author{
Huaiquan Zang ${ }^{1}$, Degang $\mathrm{Lv}^{1}$ and Yan Dai ${ }^{2}$ \\ ${ }^{1}$ School of Electrical Engineering, Yanshan University, QinHuangdao 066004, \\ China \\ ${ }^{2}$ Department of information Engineering, College of Tangshan, Tangshan, 063000, \\ China \\ hqzang@hotmail.com
}

\begin{abstract}
For dynamic mathematical model of permanent magnet synchronous motor (PMSM) applied in electric vehicles, to reduce the ripple of the speed of electric vehicles in the driving process and to improve anti-interference and fast tracking ability, control strategy based on fuzzy and auto-disturbances-rejection was proposed. The fuzzy part of the system instead of hysteresis comparator and selector switching table of the traditional DTC control, reduces the flux and torque ripple and earns superior performance. The active-disturbance-rejection (ADR) technology was applied to the speed controller to compensate system perturbation on real-time. The simulation results show that the controller based on fuzzy and active-disturbance-rejection have the advantages that flux linkage and torque ripples are small, the speed tracking is faster and steady precision is higher.
\end{abstract}

Keywords: Electric vehicle, PMSM, Fuzzy control, Active disturbance rejection control, DTC

\section{Introduction}

Along with the increasing seriousness of environmental pollution, energy conservation and emissions reduction, the development of new energy has become the world's top priority. Electric vehicle with its advantages of low noise, no pollution and zero emissions, has become the development trend of modern cars. Electric vehicle with motor control system is one of the key technologies of electric vehicles, which determines the overall performance of electric vehicles. Because of the influence of vehicle use, the electric car motor needs performances, such as overload capacity of strong, fast torque response, wide speed range, high power density and low torque ripple. Compared with DC motor, induction motor and switched reluctance motor, permanent magnet synchronous motor is more suitable for the electric car motor drive system, and widely used [1].

At present, the electric vehicle with permanent magnet synchronous motor control system usually adopts direct torque control and vector control. Compared with the vector control, direct torque control does not need complex vector transformation. There is no current closed loop structure and PWM signal generator. Its control structure is simple, and motor parameter influence is small. It can obtain better dynamic performance [2]. But the traditional direct torque control employs hysteresis comparator and select switch table, leading to large torque and flux ripple.

In this paper, the fuzzy control and the immunity control are applied to the electric vehicle motor direct torque control system. The simulation results show that the proposed method can suppress the torque ripple effectively. The system has the 
advantages of high control precision, fast response, and strong anti-interference ability to improve the performance of the electric vehicle.

\section{Permanent Magnet Synchronous Motor Model}

In dynamic analysis of PMSM, we use the Park transformation by coordinating the three phase system into two phase rotating $\mathrm{d}-\mathrm{q}$ coordinate system generally. The transformed dynamic equation is as follow:

$$
\left\{\begin{array}{l}
\frac{d}{d t} i_{d}=\frac{1}{L_{d}} u_{d}-\frac{R}{L_{d}} i_{d}+\frac{L_{q}}{L_{d}} p \omega_{r} i_{q} \\
\frac{d}{d t} i_{q}=\frac{1}{L_{q}} u_{q}-\frac{R}{L_{q}} i_{q}+\frac{L_{d}}{L_{q}} p \omega_{r} i_{d}-\frac{\varphi_{s} p \omega_{r}}{L_{q}} \quad(1) \text { Where, } u_{d}, u_{q} \text { is the d-q axes stator } \\
T_{e}=\frac{3}{2} p\left[\varphi_{r} i_{q}+\left(L_{d}-L_{q}\right) i_{d} i_{q}\right] \\
T_{e}-T_{m}=J \frac{d \omega_{r}}{d t}+B \omega_{r}
\end{array}\right.
$$

flux; $L_{d}, L_{q}$ is the d-q axes inductances; $R$ is the stator resistance; $\omega_{r}$ is the rotor angular velocity; $\varphi_{r}$ is rotor flux; $p$ is the number of poles; $T_{e}$ is the electromagnetic torque; $T_{t}$ is the motor load torque; $J$ is the moment of inertia; $B$ is the viscous friction factor.

\section{Direct Torque Control of Permanent Magnet Synchronous Motor}

Motor and inverter are considered as a whole in direct torque control. We use analysis method about space vector and mode of stator magnetic field orientation to control static flux and electromagnetic torque directly. Fig.1 shows diagram of motor flux.

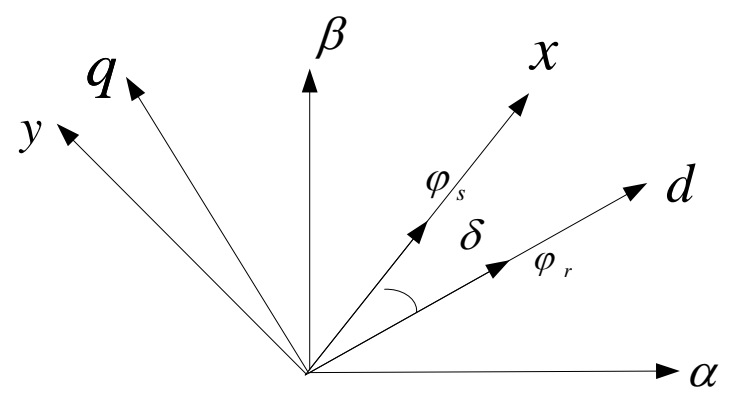

Figure 1. Motor Flux

According to the motor control theory, we can get non-salient pole permanent magnet synchronous motor electromagnetic torque.

Torque equation from motor control theory is:

$T_{e}=\frac{3 p}{2 L_{d}}\left|\varphi_{s}\right| \varphi_{r} \sin \delta$ (2)Where, $\varphi_{s}$ is the stator flux; power angle $\delta$ is the angle between $\varphi_{s}$ and $\varphi_{r}$. From (2), in the case of remaining stator flux amplitude, $T_{e}$ and its change are related with power angle $\delta$ and its change. In constitution of steady state, remain load angle $\delta$, the stator flux $\varphi_{s}$ and rotor flux $\varphi_{r}$ will be synchronous rotation. In the case of dynamic, stator flux $\varphi_{s}$ and $\varphi_{r}$ rotate in different speeds, and power angle $\delta$ changes. Electrical time constant is much less than mechanical time constant. It is easy to change the speed of the stator flux come to change the size of the Angle to control the torque. 
Changing the speed of the stator flux $\varphi_{s}$ equates to choose different stator voltage vector. DTC system operates under the two phase stator coordinate system.

Basic voltage vector is: $u_{s}=\frac{2}{3}\left(u_{a}+u_{b} e^{j 2 \pi / 3}+u_{c} e^{j 4 \pi / 3}\right)$ (3)Where, $u_{a}, u_{b}$ and $u_{c}$ are Phase voltages of the threephase stator winding. The three-phase voltage inverter have a total of 8 voltage vectors, including 6 operating voltage vectors and 2 zero voltage vectors (000), (111). Showed as Figure 2, direct torque controller controls the rotation speed and direction of the stator flux by selecting different voltage vector to control the size of the power angle to achieve the purpose of control torque.

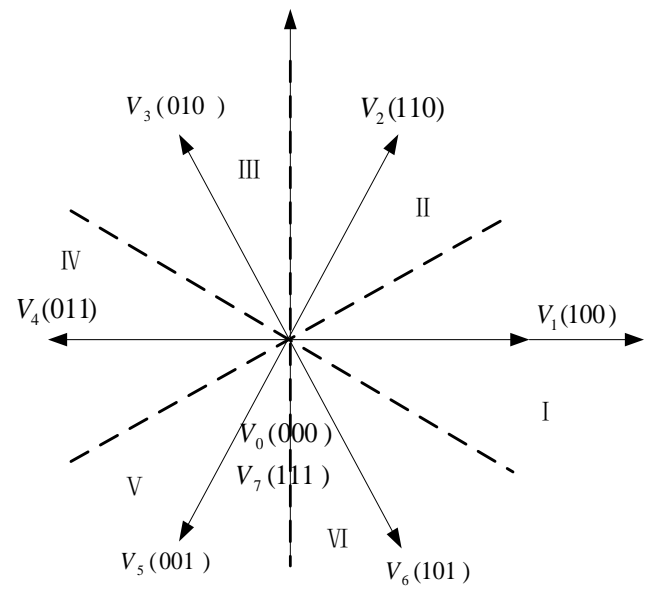

Figure 2. Voltage Space Vector

\section{The Design of Fuzzy Controller}

Fuzzy control is an artificial intelligence control method which is based on expert experience and reasoning judgment. It has good ability to control the nonlinear control system. Fuzzy controller generally contains three parts: Fuzzification, Fuzzy Reasoning and Defuzzification [11].

The inputs of the fuzzy controller are that: Torque error $T$, flux linkage error $F$, flux position angle $\theta$, the output vector $V . T$ And $F$ fuzzy universe is [-2.5 2.5], Two fuzzy variables are given 4 language values as [NB NS PS PB], In order to reduce the number of fuzzy rules, according to equation (4), the stator flux linkage Angle should be mapped from $2 \pi$ to $(-\pi / 6, \pi / 6)$

$$
\left.\theta=\theta_{j}-\frac{\pi}{3} \mid \frac{\theta_{j}-\frac{\pi}{6}}{\frac{\pi}{3}}\right\rfloor
$$

Where, $\theta$ is the angle after be mapped. $\theta_{j}$ is the angle of stator flux linkage. Each membership function of fuzzy variables is showed as Fig.3. The reasoning process of fuzzy controller uses Mamdani algorithm, the defuzzification uses Max-min algorithm. 


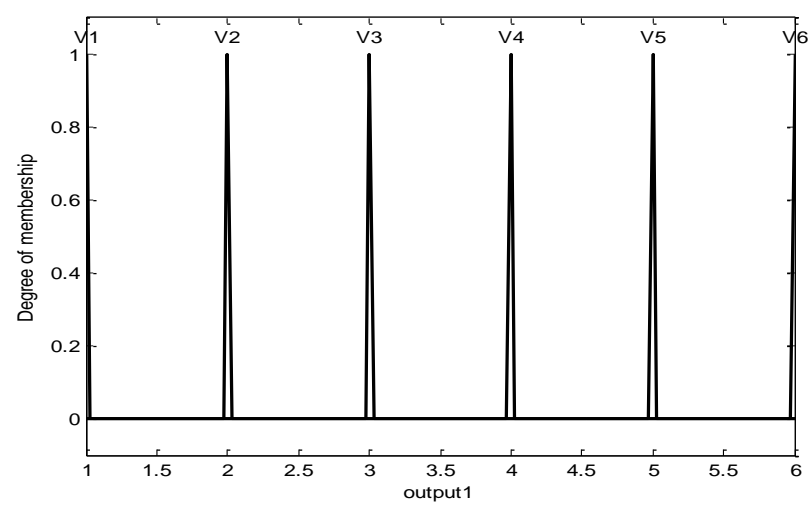

(a) Membership Functions of Voltage Space Vector

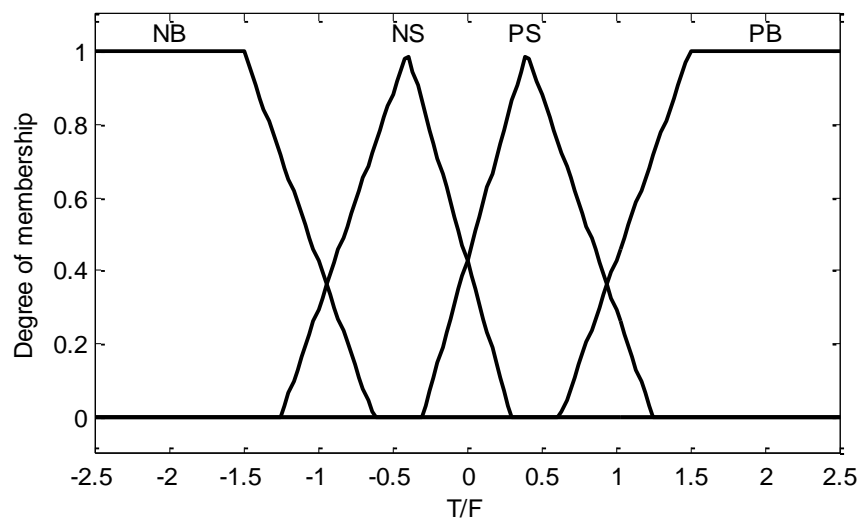

(b) Membership Functions of Flux Linkage and Torque Error

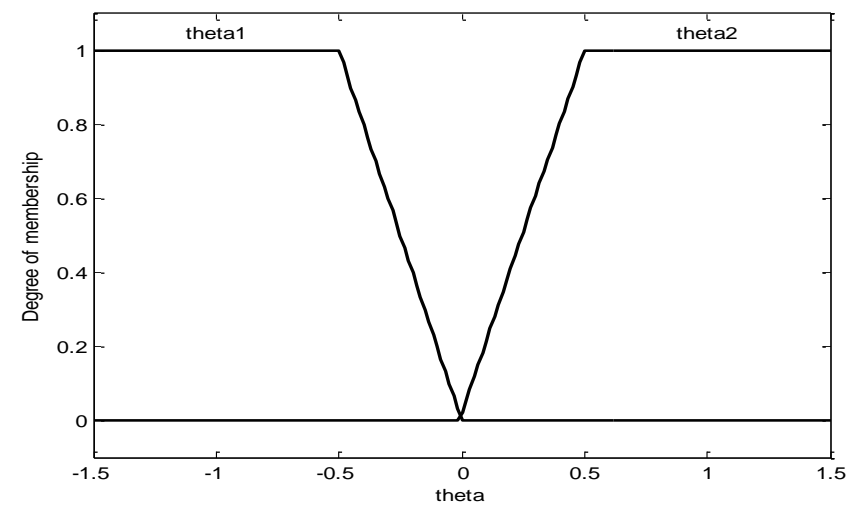

(c) Membership Function of the Flux Linkage Angle

Figure 3. Diagram of Fuzzy Membership Function 


\section{Auto Disturbance Rejection Controller}

\subsection{The Basic Principle of ADRC}

Active disturbance rejection control (ADRC) is a new nonlinear digital control technology. (ADRC) is mainly composed of nonlinear tracking differentiator (TD), extended state observer (ESO) and nonlinear state error feedback (NLSEF) [12]. In the case of a first order system, TD used to arrange the transition process and realize input signal fast tracking without overshoot. It can extract good differential signal. ESO observes the state and the disturbance of system; NLSEF gets controlled quantity through TD and ESO evaluates nonlinear combination of error. In the case of a first order system, the structure is showed as Figure 4.

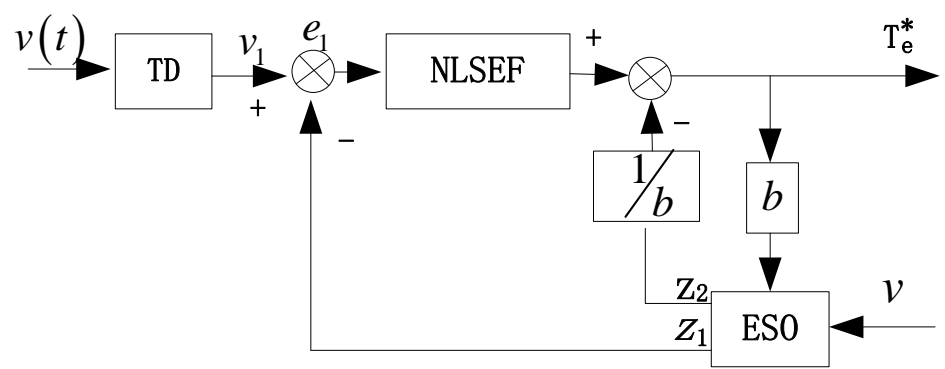

Figure 4. Diagram of ADRC Structure

Supposed First-order system is:

$$
\left\{\begin{array}{l}
\dot{x}=f(x, t)+b u(t) \\
y=x
\end{array}\right.
$$

Where, $x$ is measurable state, $f(x, t)$ is disturbance, $b$ is parameter, $u(t)$ is system input.

First order nonlinear Tracking differentiator (TD) is:

$$
\left\{\begin{array}{l}
\varepsilon_{1}=v_{1}-v(t) \\
\dot{v}_{1}=-k_{1} \text { fal }\left(\varepsilon_{1}, \alpha_{1}, \beta_{1}\right)
\end{array}\right.
$$

Second-order extended state observer (ESO) is:

$$
\left\{\begin{array}{l}
\varepsilon_{2}=z_{1}-v \\
\dot{z}_{1}=z_{2}-k_{2} \text { fal }\left(\varepsilon_{2}, \alpha_{2}, \beta_{2}\right) \\
\dot{z}_{2}=-k_{3} \text { fal }\left(\varepsilon_{2}, \alpha_{2}, \beta_{2}\right)
\end{array}\right.
$$

NLSEF nonlinear state error feedback control law is:

$$
\left\{\begin{array}{l}
\varepsilon_{3}=v_{1}-z_{1} \\
u_{0}(t)=k_{4} f a l\left(\varepsilon_{3}, \alpha_{3}, \quad \beta_{3}\right) \\
u(t)=u_{0}(t)-\frac{z_{2}}{b_{0}}
\end{array}\right.
$$

Where:

$$
f a l(\varepsilon, \alpha, \beta)= \begin{cases}\frac{\varepsilon}{\beta^{1-\alpha}} & |\varepsilon| \leq \beta \\ \operatorname{sgn}(\varepsilon)|\varepsilon|^{\alpha} & |\varepsilon|>\beta\end{cases}
$$


Where: $v(t)$ is input signal, $v$ is feedback signal, $v_{1}$ is transient process that TD extracts $v(t) ; y_{t}$ is output signal of controlled object; $z_{1}$ is the state variable of controlled object which is estimated real-time by ESO; $z_{2}$ is disturbing signal of controlled object which is estimated real-time by ESO; $\mathrm{e}_{1}$ is the error signal between $v_{1}$ and $z_{1} ; b_{0}$ is compensation factor.

\subsection{Design of Speed Control}

In order to simplifying the controller and improving the dynamic performance of system, the speed controller in this paper adopts first-order ADRC. The ADRC consists of two parts, ESO and NLSEF, which TD is omitted.

The motion equation of permanent magnet synchronous motor is:

$$
\frac{d \omega_{r}}{d t}=\frac{p}{J}\left(T_{e}-T_{l}\right)-\frac{B \omega_{r}}{J}
$$

Where, $T_{l}$ is load torque, $J$ is rotational inertia, $T_{e}$ is electromagnetic torque, $p$ is number of pole-pairs, $B$ is coefficient of viscosity, $\omega_{r}$ is motor speed. According to ADRC theory, $p T_{l} / J$ and $B \omega_{r} / J$ are taken as disturbance of system. Then formula (10) is written as:

$$
\frac{d \omega_{r}}{d t}=b u+f(t)
$$

Where, $b=p / J, f(t)=-p T / J-B \omega_{r} / J, u=T_{e}$.

Because of the speed loop controller needs only first-order ADRC, so the ESO and NLSEF are showed as equation (7) and (8). The structure of controller is showed as Figure 5 .

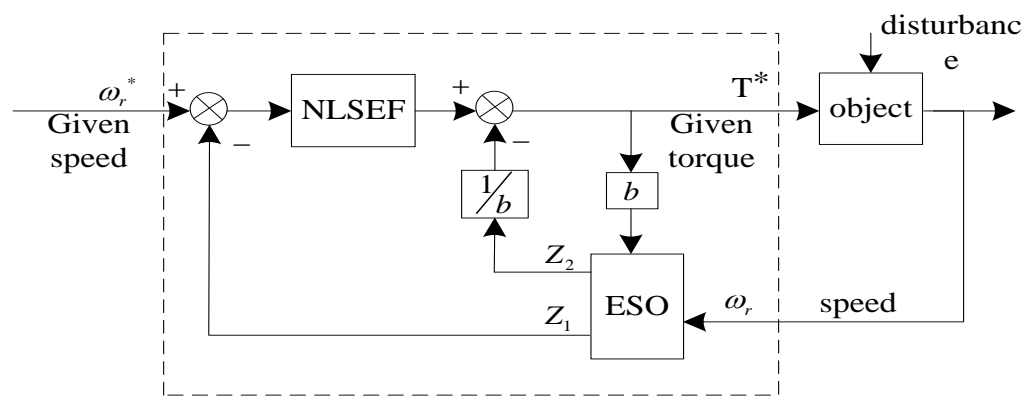

Figure 5. The Structure of Speed Controller based on ADR

\section{Simulation and Experimental Analysis}

In Matlab/simulink, the model of permanent magnet synchronous motor direct torque control based on the fuzzy and the immunity control is developed for simulation, then we compare the result of the model with that of the traditional direct torque control and fuzzy control. The test permanent magnet synchronous motor with the data parameters: stator resistance $R_{S}=2.8750, L_{d}=L_{q}=8.5 e^{-3} \mathrm{H}$, rotary inertia $J=0.0008 \mathrm{~kg} \cdot \mathrm{m}^{2}$, Permanent magnet flux linkage $\psi_{r}=0.175 \mathrm{~Wb}$. The damping coefficient of the motor $F=0$, number of pole-pairs about motor $p=4$, the data parameters about Auto Disturbance Rejection 
Controller $\alpha_{1}=0.7, \beta=0.01, K_{2}=170, K_{3}=500, K_{4}=5000, b_{0}=500$. The PI controller parameters are as follows: $K_{p}=0.2, K_{i}=0.1$.

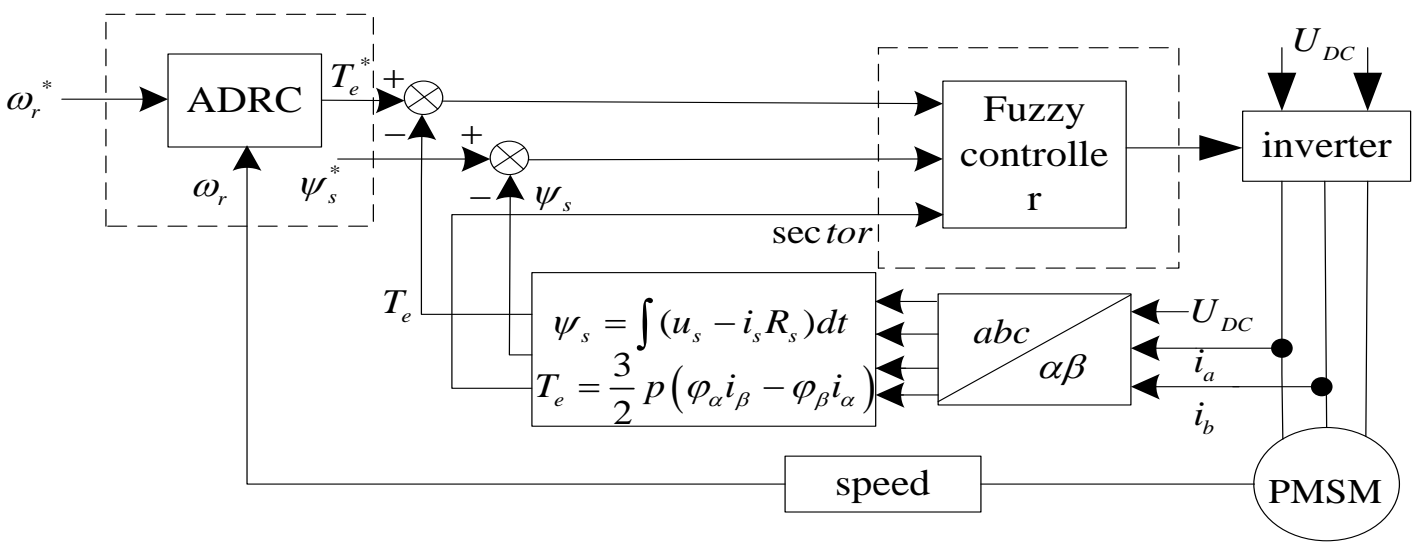

Figure 6. Diagram of Fuzzy and ADR Direct Torque Control System

The simulation conditions are: the given speed is $1000 \mathrm{r} / \mathrm{min}$, then adding $1 N \cdot m$ load at $0.03 \mathrm{~s}$, the models of traditional DTC and the DTC based on the fuzzy and the immunity are studied in Matlab/Simulink. The diagrams about torque, current, flux linkage are showed as Figure 7, Figure 8 and Figure 9. From these figures, we can see that the ripple of waveform from traditional direct torque control is large, that from new direct torque control which is added fuzzy and ADR control is improved obvious. The ripples of torque, current, flux are reduced sharply. Hysteresis comparator and selector switching table of the traditional DTC control are instead of the fuzzy part of the system. According to the more precise fuzzy inference, the system compensates magnetic torque on real-time.

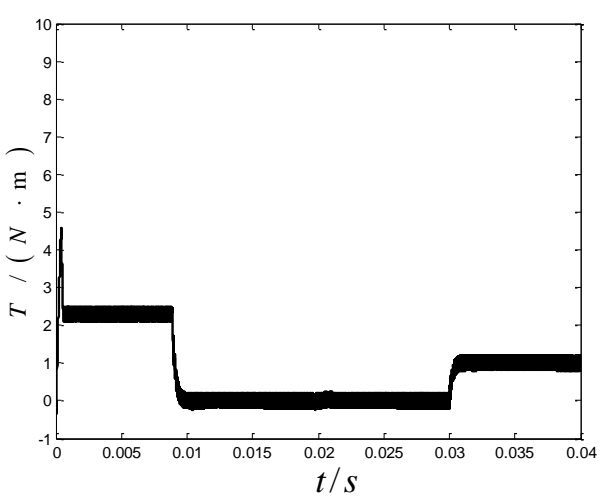

(a) Traditional DTC

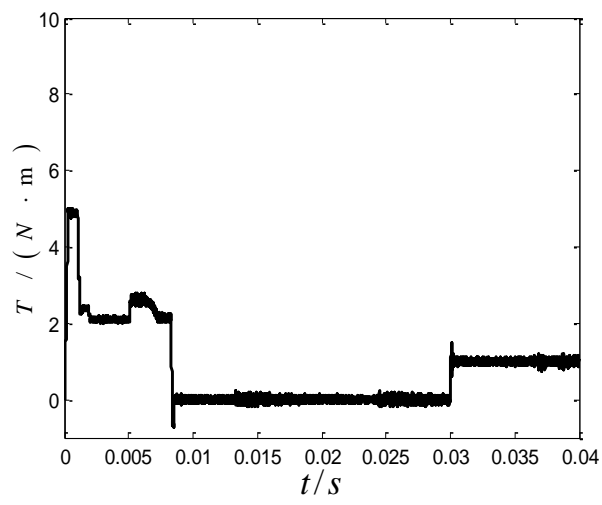

(b) DTC based on fuzzy and ADR

Figure 7. Diagram of Electromagnetic Torque Waveforms 


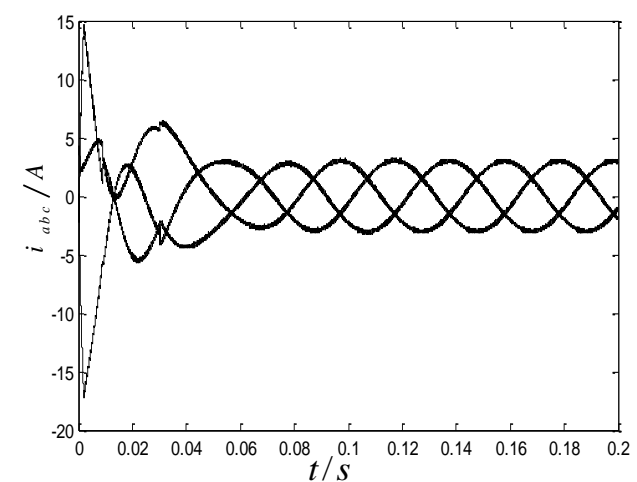

(a) Traditional DTC

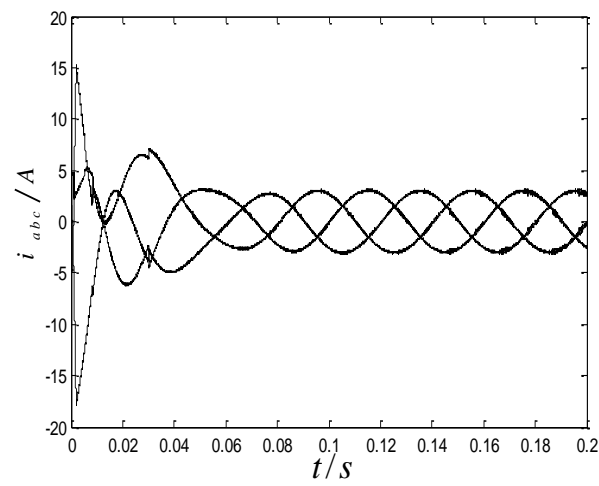

(b) DTC based on fuzzy and ADR

Figure 8. Diagram of Three-phase Current Waveforms

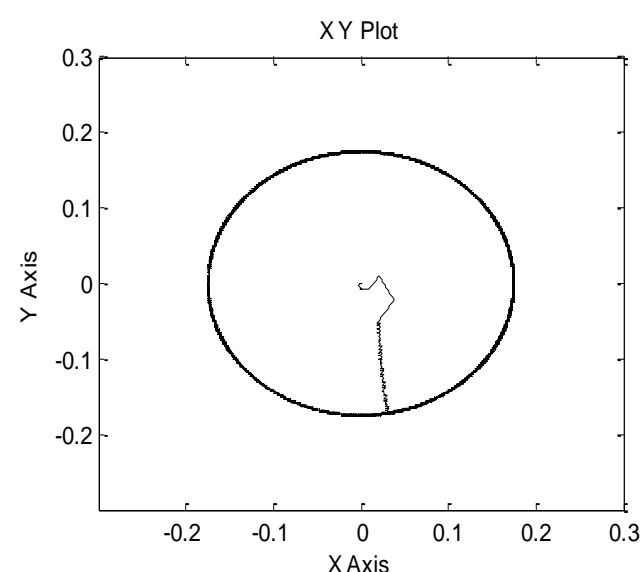

(a) Traditional DTC

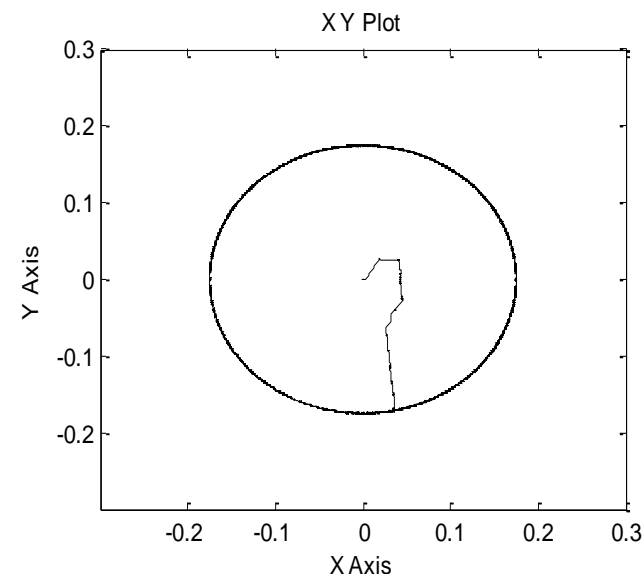

(b) DTC based on fuzzy and ADR

Figure 9. Diagram of Flux Waveforms

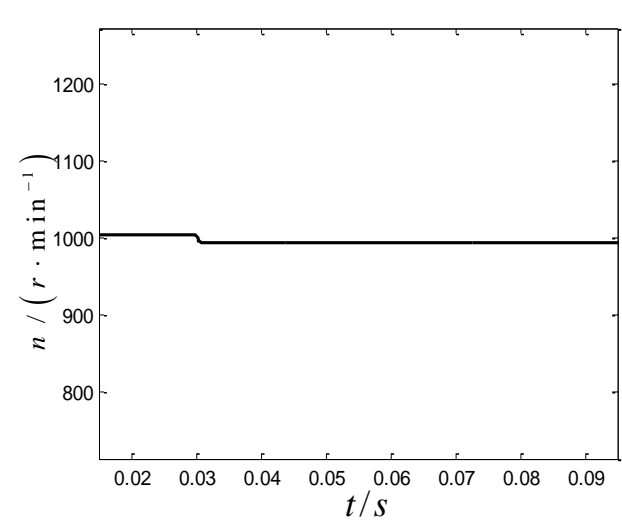

(a) Traditional DTC

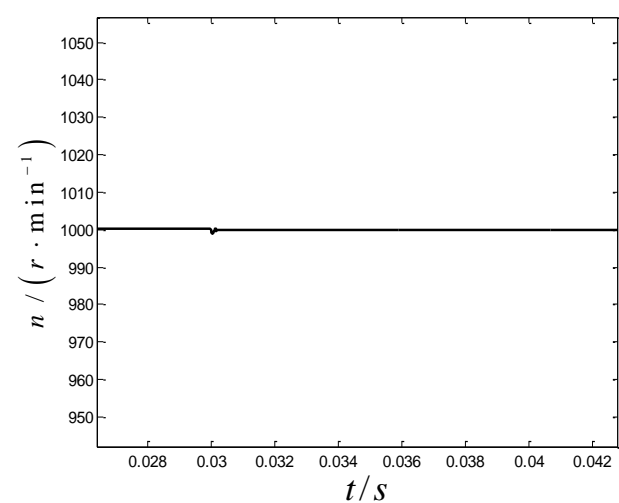

(b) DTC based on fuzzy and ADR

Figure 10. Waveform of Sudden Load Speed Changing

The climbing operation is illustrated in Figure 10. Simulation conditions: No-load running with the initial speed $1000 \mathrm{r} / \mathrm{min}$, then adding $2 \mathrm{~N} \cdot \mathrm{m}$ load at $0.03 \mathrm{~s}$ which is thought that the car encounters the resistance. The traditional DTC has obvious speed 
ripple, more the speed is change. The DTC added fuzzy and ADRC can see the tiny ripple just when the figure is amplified, and it can return the given speed fast.

Speed changing operation is showed in Figure 11. Initial velocity is $1000 \mathrm{r} / \mathrm{min}$. The given speed is changed to $600 \mathrm{r} / \mathrm{min}$ at $0.05 \mathrm{~s}$ and changed to $1200 \mathrm{r} / \mathrm{min}$ at $0.1 \mathrm{~s}$. From Figure 11, we see that both algorithms can make the motor track the given speed fast. After magnifying the Figure 11, we get that the system based on fuzzy and ADRC tracks the speed faster and more exactly from Figure 12.

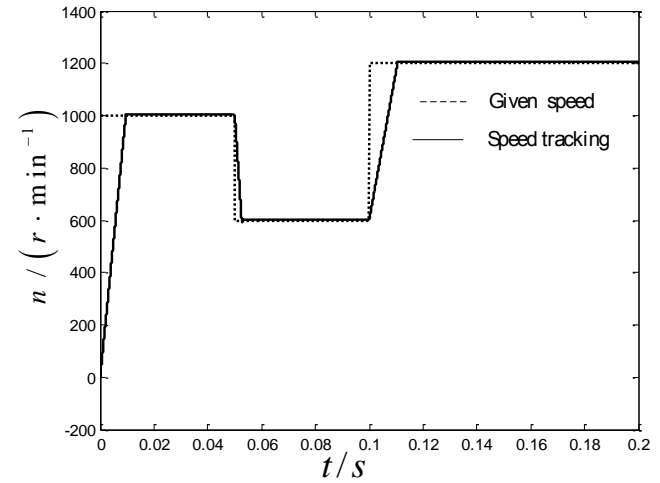

(a) Traditional DT

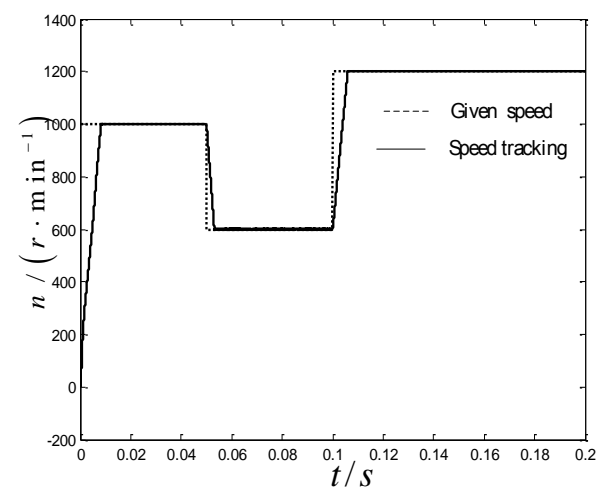

(b) DTC based on Fuzzy and ADR

Figure 11. Waveform of Speed Tracking

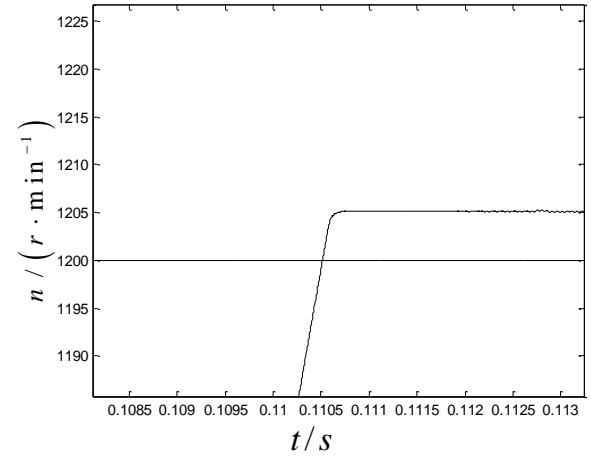

(a) Traditional DTC

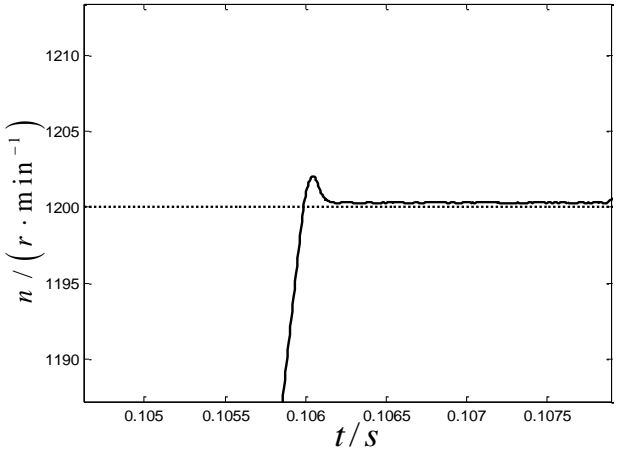

(b) DTC based on fuzzy and ADR

\section{Figure 12. Waveform of Speed Tracking Magnifying}

\section{Conclusion and Further Research}

The PMSM DTC model based on fuzzy and ADRC is built in this paper and made a simulation operation. The simulation results show that the controller based on fuzzy and auto-disturbances-rejection have the advantages that magnetic chain, torque ripple is small, the speed tracking fast and steady precision higher.

In the next step, we plan to improve the accuracy of the obtained flux and torque, which plays a significant role in the PMSM DTC system.

\section{References}

[1] Jung W P, Dae H K, Jong M K. "Improvement of Control Characteristics of Interior Permanent-magnet Synchronous Motor for Electrical Vehicle”. IEEE Transactions on Industry Application, vol.37, no.6, (2001), pp. 1754-1760. 
[2] Su Li. "Asynchronous motor direct torque control”, China Machine Press, (1999).

[3] Yanping Xu, Yanru Zhong. "Sectors Subdivision and Duty Ratio Control Combined DTC for PMSM". Chinese Society for Electrical Engineering, vol.29, no.3, (2009), pp. 102-108.

[4] Xiaozhong Liao, Liwei Shao. "The Twelve-Section Control Methods of Direct Torque Control". Chinese Society for Electrical Engineering, vol.26, no.6, (2009), pp. 167-173.

[5] Dan Sun, Yikang He. "Space Vector Modulated Based Constant Switching Frequency Direct Torque Control for PMSM". Chinese Society for Electrical Engineering, vol.25, no.12, (2005), pp. 112-116.

[6] Habetler T G. "Direct Torque Control of Induction Machines Using Space Vector Modulation". IEEE Trans. on Industry Applications, vol.28, no.5, (1992), pp. 1045-1053.

[7] Lascu C, Boldea I, Blaabjerg F. "A Modified Direct Torque Control for Induction Motor Sensorless Drive”. IEEE Trans. on Industry Applications, vol.36, no.1, (2000), pp. 122-130.

[8] Guangye Li, Jianru Wan, Yingpei Liu, et al. "Direct Torque Control of Permanent Magnet Synchronous Motor Based on Fuzzy Zero-vector". Electric Power Automation Equipment, vol.29, no.9, (2009), pp 31-35.

[9] Hongping Jia, Yikang He. "Study on Null Vector in A Direct Torque Controlled Permanent Magnet Synchronous Motor". Electric Drive, vol.36, no.4, (2006), pp. 13-16.

[10] Jingqing Han. "Active Disturbance Rejection Control Technology". National Defence Industry Press, (2008).

[11] Dan Sun, Yikang He. "Direct Torque Control of A Permanent Magnet Synchronous Motor Based on Fuzzy Logic". China Electrotechnical Society, vol.18, no.1, (2006), pp. 33-38.

[12] Han J, "From PID to Active Disturbance Rejection Control". IEEE Transactions on Industrial Electronics, vol.56, no.3, (2009), pp. 900-906. 